\title{
Chemical exposure as etiology in developmental origin of adult onset human cancer
}

\section{Kirsi Vähäkangas*}

School of Pharmacy, University of Eastern Finland, Kuopio, Finland

\section{Edited by:}

Dennis Smith, Pfizer Global Research and Development, USA

\section{Reviewed by:}

Silvia Gratz, University of Aberdeen, UK

Dennis Smith, Pfizer Global Research and Development, USA

\section{*Correspondence:}

Kirsi Vähäkangas, Faculty of Health Sciences, University of Eastern Finland, P.O. Box 1627, Fl-70211 Kuopio, Finland.

e-mail:kirsi.vahakangas@uef.fi
Chemical exposures are in principle preventable causes of cancer. People are exposed to chemicals already during fetal period and the possibility of disturbances in human development by chemical compounds leading to cancer later in life has been proven by diethylstilbestrol. The mechanisms most probably include epigenetic modifications of promoter regions of key genes. The world-wide increases in cancer incidence and concurrent increase in the number and quantity of chemicals in the environment raises concerns about a link between these two. Developmental origin and related mechanisms in chemically induced human cancer are worth pursuing.

Keywords: transplacental carcinogenesis, fetal exposure, epigenetic modifications, environmental chemicals, endocrine disruptors

\section{CHEMICAL ETIOLOGY OF CANCER}

Many chemical compounds are known to cause cancer in humans, smoking and lung cancer (e.g., Loeb et al., 1984; IARC, 1986), and aflatoxin and liver cancer (e.g., Wogan, 1992; Wild and Montesano, 2009) as prime examples. Chemicals are theoretically preventable causes of cancer, especially when it comes to lifestyle associated and occupational exposures. Thus it is of utmost importance to know which compounds, at what concentrations and at what time are the most critical for human cancer. It has long been known that also the duration of exposure, time of first exposure and cessation of exposure play a role, for instance in tobacco-related cancers in humans (IARC, 1986). New information of fetal exposures and their mechanisms, mechanisms of action of chemicals, and the emerging concept of developmental origin of diseases open interesting views on chemical carcinogenesis.

Epidemiological evidence exists on the increase of dysfunction and cancer of the reproductive system during the past decades with concurrent increase of endocrine disruptors in the environment (Maffini et al., 2006). In men the increased incidence of testicular cancer, cryptorchidism, hypospadias, and subfertility are linked and thought to represent one syndrome, the testicular dysgenesis syndrome (TDS) with environmental factors, like persistent organic pollutants (POP) playing a role in the etiology (Olesen et al., 2007). Prenatal animal exposure to phthalates has also been described to induce TDS-like syndrome in rats. Exposure of mice during fetal period to bisphenol A, the ubiquitous model endocrine disruptor (Maffini et al., 2006), and to diethylstilbestrol, an estrogenic drug (Newbold et al., 2006) induces changes in reproductive organs that persist through life and in the case of diethylstilbestrol even through several generations. Such studies on environmental endocrine disruptors have given credence to the concept of developmental origin of chemically induced adult onset diseases.
The developmental origin of cancer in humans is proven in connection with ionizing radiation and diethylstilbestrol (reviewed in Birnbaum and Fenton, 2003). However, implications of many more exist, for instance in animals dioxins during prenatal development sensitize breast to later carcinogenic insult and in humans some parental exposures (pesticides, hydrocarbons) are related to childhood leukemia. All available information summed up, there are good reasons to hypothesize that the effects of prenatal exposures to carcinogenic chemicals in general do not end in childhood, but may well extend to adulthood.

\section{FETAL EXPOSURE}

It is emerging that most compounds to which the mother is exposed during pregnancy are transported more or less at the same concentrations also to fetal circulation (Barr et al., 2007; Vähäkangas and Myllynen, 2009). As shown in human placental perfusion, this applies to many known or putative human chemical carcinogens, like NDMA (Annola et al., 2009), benzo(a)pyrene (Mathiesen et al., 2009; Karttunen et al., 2010), acrylamide and glycidamide (Sörgel et al., 2002; Annola et al., 2008), aflatoxin B1 (Partanen et al., 2010), and phthalates (Mose et al., 2007). Indicating biologically significant exposure, benzo $(a)$ pyrene-diol epoxide-DNA adducts (Manchester et al., 1988; Topinka et al., 2009) and aflatoxin B1-DNA adducts (Hsieh and Hsieh, 1993) have been shown in human maternal and cord blood as well as in human placenta. Importantly, both fetus and placenta can activate carcinogens, although at a much lower level than maternal liver (reviewed e.g., by Myllynen et al., 2009).

Paired samples of maternal and cord blood give an indication of the extent of transfer to the fetus in vivo. Both PCBs (Bergonzi et al., 2009) and structurally related polybrominated diphenyl ether (PBDEs) flame retardants (Mazdai et al., 2003) are found in cord blood in similar concentrations as in the mother with a wide variation geographically. PBDEs are carcinogenic in 
animals and interfere with sex hormone receptors with prenatal exposure leading to disturbance of male and female reproductive organs (reviewed by Costa et al., 2008). Endocrine disruptors have been shown in maternal and cord blood as well as in placenta, and in breast milk, too. Furthermore, the concentration of bisphenol $\mathrm{A}$ in amniotic fluid exceeds the concentration in maternal blood implicating accumulation of bisphenol $\mathrm{A}$ in fetal compartment (reviewed in Maffini et al., 2006).

\section{TRANSPLACENTAL CARCINOGENESIS}

Animal studies have proven the possibility of cancer caused due to exposure through the placenta during fetal period (reviewed by Anderson et al., 2000; Birnbaum and Fenton, 2003). Some industrial chemicals and drugs, as well as radiation have been shown to induce tumors in adult offspring when pregnant animals are treated, with an increase in incidence if the treatment is repeated in adulthood. Genotoxic chemical carcinogens induce many different types of cancers transplacentally: for instance DMBA induces respiratory tumors in mice and hamster, and ovarian, uterine and lymphoid tumors in mice; ENU induces melanomas in hamster and respiratory tumors, nervous system tumors and kidney tumors in hamster and mice, and ovarian and uterine tumors in mice. Also, a well-known animal model for glioma is tumor formation in offspring of rats treated with ethylnitrosourea at day 15 of pregnancy (Martin-Villalba et al., 2008). Developmental changes in mammary gland of rodents by chemicals have been shown by a variety of chemicals, e.g., sex hormones and Ah-receptor agonists, and may lead to increased susceptibility to breast cancer (for a recent extensive review see Rudel et al., 2011).

Diethylstilbestrol (DES) and other endocrine disruptors are transplacental carcinogens in animals (reviewed in Birnbaum and Fenton, 2003; Newbold et al., 2006). Prenatal exposure to DES induces tumors in both female and male reproductive organs and genistein, a natural phytoestrogen, increases mammary cancer in female offspring. Bisphenol A, a ubiquitous xenoestrogen to which people are widely exposed, disturbs the development of reproductive organs with the development of cancer in rodents (reviewed by Maffini et al., 2006; Soto et al., 2008). Both of these chemicals affect histone methyltransferase in mouse mammary gland after in utero exposure (Doherty et al., 2010). The fungicide vinclozolin and the pesticide methoxychlor induce a wide variety of abnormalities when rodents are exposed early in prenatal development (Anway et al., 2006; Anway and Skinner, 2008). These transgenerational effects include breast and prostate tumors and are associated with epigenetic alterations in relevant tissues (Anway et al., 2006; Skinner, 2007; Zama and Uzumcu, 2009).

Although there is only one proven transplacental chemical carcinogen in humans, diethylstilbestrol (Veurink et al., 2005), many more are implicated by epidemiological studies (reviewed in Birnbaum and Fenton, 2003). Childhood leukemia is associated with many chemicals, like hydrocarbons, solvents, plastics, and pesticides. Parental occupational exposure to chemicals and smoking is also a risk factor for childhood cancers. It is of great concern that the increased susceptibility to cancer development by endocrine disruptors seems to extend to several generations in animals (Anway et al., 2006; Newbold et al., 2006; Skinner, 2007). This has a possible explanation in heritable epigenetic modifications by chemicals.

\section{EPIGENETIC MODIFICATIONS AND OTHER MECHANISMS INDUCED BY CHEMICALS RELATED TO CANCER}

In addition to mutations in carcinogenesis related genes, aberrant patterns of epigenetic modifications are typical features of human cancers and epigenomics is gaining momentum in both mechanistic and clinical aspects of cancer, including chemical carcinogenesis (Esteller, 2007; Reamon-Buettner et al., 2008). Of the various epigenetic modifications especially methylation patterns of genes have been shown as an important feature of clinical cancers. Several cancers, where environmental carcinogens are known to play a role, display promoter hypermethylation of tumor suppressor genes and methylation aberrations also in other genes relevant to carcinogenesis.

In lung cancer patients, aberrant methylation patterns can be detected in serum DNA at all stages of tumor development (e.g., Esteller et al., 1999, reviewed by Pfeifer and Rauch, 2009). In cultured human bronchial epithelial cells cigaret smoke condensate can change gene expression patterns (Jorgensen et al., 2004; Hu et al., 2009) and induce progressive hypermethylation (Liu et al., 2010). That such modifications can occur in vivo has been implicated in the study by Launay et al. (2009). They reported that smoking induces nucleic acid demethylase activity leading to decreased promoter region methylation of the gene for MAO-B enzyme, a change that can persist for years. It is of interest in this context that tobacco leaves contain MAO-A inhibitors and that down-regulation of MAO-A seems to be one of the most consistent features of cancer tissue in addition to being related to other diseases, like cardiovascular and psychiatric conditions (Rybaczyk et al., 2008; Launay et al., 2009).

In breast cancer patients significant promoter hypermethylation of PTEN and p14ARF, regulators of p53 (Barekati et al., 2010) and RASSF1A, DAP-kinase, and APC (Dulaimil et al., 2004) have been found in tumor tissue and serum. The most important chemicals related to breast cancer are estrogens, and both estrogenic drugs and environmental estrogens (xenoestrogens) have been shown to alter promoter methylation of key genes. In mice diethylstilbestrol, the model estrogen changes expression of cell growth, differentiation, and adhesion related genes in uterus of female pups of pregnant mice treated with diethylstilbestrol (Newbold et al., 2007). One of the genes is homeobox A10; its developmental pattern of expression changes by prenatal bisphenol A and this is associated with hypermethylation of promoter region and intron of this gene (Smith and Taylor, 2007; Bromer et al., 2010). Importantly, the altered methylation pattern induced during prenatal period persisted until adulthood. In spherical cell colonies grown from normal human mammary epithelial cells, the so-called mammospheres, diethylstilbestrol hypermethylates the promoter of microRNA miR-9-3, which is associated to p53 regulated apoptosis (Hsu et al., 2009). Recently Bromer et al. (2010) showed that prenatal exposure of mice to the ubiquitous xenoestrogen bisphenol A also changes the methylation pattern of the HoxA gene, but to different direction than diethylstilbestrol inducing hypomethylation of the promoter. The decreased methylation induced higher sensitivity of the promoter to estrogen. Permanently increased 
sensitivity to estrogens could lead to increased susceptibility to estrogen associated cancers.

In connection with breast cancer, there are other interesting mechanisms putatively affecting susceptibility of mammary tissue to carcinogenic aberrations. TCDD disturbs the development of functional mammary epithelium through Ah-receptor causing persistent aberrations both prenatally in vivo in mouse, and in vitro in mouse mammary epithelial cells (Fenton et al., 2002; Vorderstrasse et al., 2004; Collins et al., 2009; Lew et al., 2009). Transformed stem cells, the so-called cancer stem cells are probably important in the initiation of cancer (Tysnes and Bjerkvig, 2007). Savarese et al. (2007) found a correlation between stem cell populations and hormones or growth factors in 289 cord blood samples and concluded that "mitogens may drive the expansion of stem cell populations.” Since mitogenic agents may be transplacentally transported from maternal blood, it is feasible to suspect that environmental mitogens may also affect stem cells during development.

\section{DEVELOPMENTAL ORIGIN OF ADULT ONSET CANCER IN HUMAN}

The concern of developmental origin of adult onset cancer is not new. The possibility of breast cancer originating in utero was hypothesized by Trichopoulos (1990; see also Savarese et al., 2007). So far only radiation and diethylstilbestrol (Veurink et al., 2005) as prenatal carcinogens in humans have been conclusively confirmed. Notably, the vaginal adenocarcinoma in females typically induced by diethylstilbestrol is found in young women, being thus beyond the category of childhood cancers. In addition, prenatal diethylstilbestrol exposure increases the risk of breast cancer later in life, after the age of 40 (Xue and Michels, 2007), a finding supported by a mouse studies (see Newbold et al., 2006). Human fetus is much more sensitive than adult organism to endocrine disruptors, but putatively also to environmental toxicants, due to

\section{REFERENCES}

Anderson, L. M., Diwan, B. A., Fear, N. T., and Roman, E. (2000). Critical windows of exposure for children's health: cancer in human epidemiological studies and neoplasms in experimental animal models. Environ. Health Perspect. 108(Suppl. 3), 573-594.

Annola, K., Heikkinen, A. T., Partanen, H., Woodhouse, H., Segerbäck, D., and Vähäkangas, K. (2009). Transplacental transfer of NDMA and DNA adduct formation in perfused human placenta. Placenta 30, 277-283.

Annola, K., Karttunen, V., KeskiRahkonen, P., Myllynen, P., Segerbäck, D., and Vähäkangas, K. (2008). Transplacental transfer of acrylamide and glycidamide are comparable to antipyrine in perfused human placenta. Toxicol. Lett. 182, 50-56.

Anway, M. D., Leathers, C., and Skinner, M. K. (2006). Endocrine disruptor vinclozolin induced epigenetic transgenerational adult-onset disease. Endocrinology 147, 5515-5523.

Anway, M. D., and Skinner, M. K. (2008). Transgenerational effects of the endocrine disruptor vinclozolin on the prostate transcriptome and adult onset disease. Prostate 68, 517-529.

Barekati, Z., Radpour, R., Kohler, C., Zhang, B., Toniolo, P., Lenner, P., Lv, Q., Zheng, H., and Zhong, X. Y. (2010). Methylation profile of TP53 regulatory pathway and mtDNA alterations in breast cancer patients lacking TP53 mutations. Hum. Mol. Genet. 19, 2936-2946.

Barr, D. B., Bishop, A., and Needham, L. L. (2007). Concentrations of xenobiotic chemicals in the maternal-fetal unit. Reprod. Toxicol. 23, 260-266.

Bergonzi, R., Specchia, C., Dinolfo, M., Tomasi, C., De Palma, G., Frusca, T., and Apostoli, P. (2009). Distribution of persistent organochlorine pollutants in maternal and foetal tissues: data from an Italian polluted urban area. Chemosphere 76, 747-754.

on-going development with high proliferation and apoptosis, deficient detoxication capacity, and under-developed immune system and DNA-repair.

From all this a hypothesis emerges about many more chemical factors than known by now modifying the genetic code or the epigenetic patterns in different tissues at their sensitive developmental periods pre- and post-natally. Such a susceptibility state may include both genotoxic and epigenetic origin, and create sensitivity for further aberrations by the same agents with continuing exposure, like smoking, or by other chemicals, like DMBA increasing breast tumors in offspring of tamoxiphen, genistein, or TCDD-treated pregnant rodents (see Birnbaum and Fenton, 2003). Since epigenetic changes may be permanent, such sensitivities will remain until adulthood, and thus exposures throughout the life-time are probably of significance. Also genetic changes may live long in the tissues, like smoking-induced TP53 mutations (Vähäkangas et al., 2001), and accumulation of organic lipid-soluble chemicals in the susceptible body certainly does not help.

Through genetic and epigenetic events during fetal and neonatal development environmental chemicals and social drugs may thus create life-long or even heritable susceptibilities to cancer. Retrospective cohorts and newly designed long-term prospective studies on the issue of developmental origin of adult onset cancer should be pursued. Mechanistic studies on various environmental chemicals are equally important to reveal possibilities for prevention and treatment. Furthermore, toxicological testing strategies for possible developmentally induced cancer are called for (Brody et al., 2011). In the case of breast cancer, such plans for studies and testing strategies are best developed (Makris, 2011; Rudel et al., 2011; White et al., 2011). The continuing trend of young women smoking and drinking alcohol and the increasing number and quantities of industrial and agricultural chemicals in our environment make these research needs urgent.

Birnbaum, L. S., and Fenton, S. E. (2003). Cancer and developmental exposure to endocrine disruptors. Environ. Health Perspect. 111, 389-394.

Brody, J. G., Rudel, R. A., and Kavanaugh-Lynch, M. (2011). Testing chemicals for effects on breast development, lactation and cancer. Environ. Health Perspect. 119, A326A327.

Bromer, J. G., Zhou, Y., Taylor, M. B. Doherty, L., and Taylor, H. S. (2010). Bisphenol-A exposure in utero leads to epigenetic alterations in the developmental programming of uterine estrogen response. FASEB J. 24, 2273-2280.

Collins, L. L., Lew, B. J., and Lawrence, B. P. (2009). TCDD exposure disrupts mammary epithelial cell differentiation and function. Reprod. Toxicol. 28, 11-17.

Costa, L. G., Giordano, G., Tagliaferri, S., Caglieri, A., and Mutti, A. (2008). Polybrominated diphenyl ether (PBDE) flame retardants: environmental contamination, human body burden and potential adverse health effects. Acta Biomed. 79, 172-183.

Doherty, L. F., Bromer, J. G., Zhou, Y., Aldad, T. S., and Taylor, H. S. (2010). In utero exposure to diethylstilbestrol (DES) or bisphenol-A (BPA) increases EZH2 expression in the mammary gland: an epigenetic mechanism linking endocrine disruptors to breast cancer. Horm. Cancer 1, 146-155.

Dulaimil, E, Hillinck, J., Ibanez de Caceres, I., Al-Saleem, T., and Cairns, P. (2004). Tumor suppressor gene promoter hypermethylation in serum of breast cancer patients. Clin. Cancer Res. 15, 6189-6193.

Esteller, M. (2007). Cancer epigenomics: DNA methylomes and histone-modification maps. Nat. Rev. Genet. 2, 286-298.

Esteller, M., Sanchez-Cespedes, M., Rosell, R., Sidransky, D., Baylin, S. B., and Herman, J. G. (1999). Detection of aberrant promoter 
hypermethylation of tumor suppressor genes in serum DNA from nonsmall cell lung cancer patients. Cancer Res. 59, 67-70.

Fenton, S. E., Hamm, J. T., Birnbaum, L. S., and Youngblood, G. L. (2002). Persistent abnormalities in the rat mammary gland following gestational and lactational exposure to 2,3,7,8-tetrachlorodibenzop-dioxin (TCDD). Toxicol. Sci. 67, 63-74.

Hsieh, L. L., and Hsieh, T. T. (1993). Detection of aflatoxin B1-DNA adducts in human placenta and cord blood. Cancer Res. 53, 1278-1280.

Hsu, P. Y., Deatherage, D. E., Rodriguez, B. A., Liyanarachchi, S., Weng, Y. I., Zuo, T., Liu, J., Cheng, A. S., and Huang, T. H. (2009). Xenoestrogeninduced epigenetic repression of microRNA-9-3 in breast epithelial cells. Cancer Res. 69, 5936-5945.

Hu, Y. C., Yang, Z. H., Zhong, K. J., Niu, L. J., Pan, X. J., Wu, D. C., Sun, X. J., Zhou, P. K., Zhu, M. X., and Huo, Y. Y. (2009). Alteration of transcriptional profile in human bronchial epithelial cells induced by cigarette smoke condensate. Toxicol. Lett. 8, 23-31.

IARC. (1986). IARC Monographs on the Evaluation of Carcinogenic Risks to Humans. Vol. 38.

Jorgensen, E. D., Dozmorov, I., Frank, M. B., Centola, M., and Albino, A. P. (2004). Global gene expression analysis of human bronchial epithelial cells treated with tobacco condensates. Cell Cycle 3, 1154-1168.

Karttunen, V., Myllynen, P., Prochazka, G., Pelkonen, O., Segerbäck, D., and Vähäkangas, K. (2010). Placental transfer and DNA binding of benzo(a)pyrene in human placental perfusion. Toxicol. Lett. 197, 75-81.

Launay, J. M, Del Pino, M., Chironi, G., Callebert, J., Peoc'h, K., Mégnien, J. L., Mallet, J., Simon, A., and Rendu, F. (2009). Smoking induces long-lasting effects through a monoamine-oxidase epigenetic regulation. PLOS ONE 23, e7959. doi:10.1371/journal.pone.0007959

Lew, B. J., Collins, L. L., O'Reilly, M. A., and Lawrence, B. P. (2009). Activation of the aryl hydrocarbon receptor during different critical windows in pregnancy alters mammary epithelial cell proliferation and differentiation. Toxicol. Sci. $111,151-162$.

Liu, F., Killian, J. K., Yang, M., Walker, R. L., Hong, J. A., Zhang, M., Davis, S., Zhang, Y., Hussain, M., Xi, S.,
Rao, M., Meltzer, P. A., and Schrump, D. S. (2010). Epigenomic alterations and gene expression profiles in respiratory epithelia exposed to cigarette smoke condensate. Oncogene 29, 3650-3664.

Loeb, L. A., Ernster, V. L., Warner, K. E., Abbotts, J., and Laszlo, J. (1984). Smoking and lung cancer: an overview. Cancer Res. 44, 5940-5958.

Maffini, M. V., Rubin, B. S., Sonnenschein, C., and Soto, A. M. (2006). Endocrine disruptors and reproductive health: the case of bisphenolA. Mol. Cell. Endocrinol. 254-255, 179-186.

Makris, S. L. (2011). Current assessment of the effects of environmental chemicals on the mammary gland in guideline rodent studies by the $\mathrm{U}$. S. environmental protection agency (U. S. EPA), organisation for economic co-operation and development (OECD), and national toxicology program (NTP). Environ. Health Perspect. 119, 1047-1052.

Manchester, D. K., Weston, A., Choi, J. S., Trivers, G. E., Fennessey, P. V., Quintana, E., Farmer, P. B., Mann, D. L., and Harris, C. C. (1988). Detection of benzo[a]pyrene diol epoxideDNA adducts in human placenta. Proc. Natl. Acad. Sci. U.S.A. 85, 9243-9247.

Martin-Villalba, A., Okuducu, A. F., and von Deimling, A. (2008). The evolution of our understanding on glioma. Brain Pathol. 18, 455-463.

Mathiesen, L., Rytting, E., Mose, T., and Knudsen, L. E. (2009). Transport of benzo[alpha]pyrene in the dually perfused human placenta perfusion model: effect of albumin in the perfusion medium. Basic Clin. Pharmacol. Toxicol. 105, 181-187.

Mazdai, A., Dodder, N. G., Abernathy, M. P., Hites, R. A., and Bigsby, R. M. (2003). Polybrominated diphenyl ethers in maternal and fetal blood samples. Environ. Health Perspect. 111, 1249-1252.

Mose, T., Knudsen, L. E., Hedegaard, M., and Mortensen, G. K. (2007). Transplacental transfer of monomethyl phthalate and mono(2-ethylhexyl) phthalate in a human placenta perfusion system. Int. J. Toxicol. 26, 221-229.

Myllynen, P., Immonen, E., Kummu, M., and Vähäkangas, K. (2009). Developmental expression of drug metabolizing enzymes and transporter proteins in human feto-placental unit. Expert Opin. Drug Metab. Toxicol. 5, 1483-1499.
Newbold, R. R., Jefferson, W. N., Grissom, S. F., Padilla-Banks, E., Snyder, R. J., and Lobenhofer, E. K. (2007). Developmental exposure to diethylstilbestrol alters uterine gene expression that may be associated with uterine neoplasia later in life. Mol. Carcinog. 46, 783-796.

Newbold, R. R., Padilla-Banks, E., and Jefferson, W. N. (2006). Adverse effects of the model environmental estrogen diethylstilbestrol are transmitted to subsequent generations. Endocrinology 147(Suppl. 6), S11S17.

Olesen, I. A., Sonne, S. B., HoeiHansen, C. E., Rajpert-DeMeyts, E., and Skakkebaek, N. E. (2007). Environment, testicular dysgenesis and carcinoma in situ testis. Best Pract. Res. Clin. Endocrinol. Metab. 21, 462-478.

Partanen, H. A., El-Nezami, H. S., Leppänen, J., Myllynen, P., Woodhouse, H., and Vähäkangas, K. H. (2010) Aflatoxin B1 transfer and metabolism in human placenta. Toxicol. Sci. 113, 216-225.

Pfeifer, G. P., and Rauch, T. A. (2009). DNA methylation patterns in lung carcinomas. Semin. Cancer Biol. 19, 181-187.

Reamon-Buettner, S. M., Mutschler, V., and Borlak, J. (2008). The next innovation cycle in toxicogenomics: environmental epigenetics. Mutat. Res. $659,158,165$

Rudel, R. A., Fenton, S. E., Ackerman, J. M., Euling, S. Y., and Makris, S. L. (2011). Environmental exposures and mammary gland development: state of the science, public health implications and research recommendations. Environ. Health Perspect. 119, 1053-1061.

Rybaczyk, L. A., Bashaw, M. J., Pathak, D. R., and Huang, K. (2008). An indicator of cancer: downregulation of monoamine oxidase-A in multiple organs and species. BMC Genomics 20, 134. doi:10.1186/1471-2164-9-134

Savarese, T. M., Strohsnitter, W. C., Low, H. P., Liu, Q., Baik, I., Okulicz, W., Chelmow, D. P., Lagiou, P., Quesenberry, P. J., Noller, K. L., and Hsieh, C. C. (2007). Correlation of umbilical cord blood hormones and growth factors with stem cell potential: implications for the prenatal origin of breast cancer hypothesis. Breast Cancer Res. 9, R29.

Skinner, M. K. (2007). Endocrine disruptors and epigenetic transgenerational disease etiology. Pediatr. Res. 61, 48R-50R.
Smith, C. C., and Taylor, H. S. (2007). Xenoestrogen exposure imprints expression of genes (Hoxa10) required for normal uterine development. FASEB J. 21, 239-246.

Sörgel, F., Weissenbacher, R., KinzigSchippers, M., Hofmann, A., Illauer, M., Skot, A., and Landersdorfer, C. (2002). Acrylamide: increased concentrations in homemade food and first evidence of its variable absorption from food, variable metabolism and placental and breast milk transfer in humans. Chemotherapy 48, 267-274.

Soto, A. M., Vandenberg, L. N., Maffini, M. V., and Sonnenschein, C. (2008). Does breast cancer start in the womb? Basic Clin. Pharmacol. Toxicol. 102, 125-133.

Topinka, J., Milcova, A., Libalova, H., Novakova, Z., Rossner, P. Jr., Balascak, I., and Sram, R. J. (2009). Biomarkers of exposure to tobacco smoke and environmental pollutants in mothers and their transplacental transfer to the foetus. Part I: bulky DNA adducts. Mutat. Res. 669, 13-19.

Trichopoulos, D. (1990). Does breast cancer originate in utero? Lancet 335, 939-940.

Tysnes, B. B., and Bjerkvig, R. (2007). Cancer initiation and progression: involvement of stem cells and the microenvironment. Biochem. Biophys. Acta 1775, 283-297.

Vähäkangas, K., and Myllynen, P. (2009). Drug transporters in the human blood-placental barrier. $\mathrm{Br}$. J. Pharmacol. 158, 665-678.

Vähäkangas, K. H., Bennett, W. P., Castren, K., Welsh, J. A., Khan, M. A., Blomeke, B., Alavanja, M. C., and Harris, C. C. (2001). p53 and Kras mutations in lung cancers from former and never-smoking women. Cancer Res. 61, 4350-4356.

Veurink, M., Koster, M., and Berg, L. T. (2005). The history of DES, lessons to be learned. Pharm. World Sci. 27, 139-143.

Vorderstrasse, B. A., Fenton, S. E., Bohn, A. A., Cundiff, J. A., and Lawrence, B. P. (2004). A novel effect of dioxin: exposure during pregnancy severely impairs mammary gland differentiation. Toxicol. Sci. 78, 248-257.

White, S. S., Stanko, J. P., Kato, K., Calafat, A. M., Hines, E. P., and Fenton, S. E. (2011). Gestational and chronic low-dose PFOA exposures and mammary gland growth and differentiation in three 
generations of CD-1 mice. Environ. Health Perspect. 119, 1070-1076.

Wild, C. P., and Montesano, R. A. (2009). Model of interaction: aflatoxins and hepatitis viruses in liver cancer aetiology and prevention. Cancer Lett. 286, 22-28.

Wogan, G. N. (1992). Aflatoxins as risk factors for hepatocellular carcinoma in humans. Cancer Res. 52(Suppl. 7), 2114-2118.

Xue, F., and Michels, K. B. (2007). Intrauterine factors and risk of breast cancer: a systematic review and meta-analysis of current evidence. Lancet Oncol. 8, 1088-1100.

Zama, A. M., and Uzumcu, M. (2009). Fetal and neonatal exposure to the endocrine disruptor methoxychlor causes epigenetic alterations in adult ovarian genes. Endocrinology 150, 4681-4691.

Conflict of Interest Statement: The authors declare that the research was conducted in the absence of any commercial or financial relationships that could be construed as a potential conflict of interest.

Received: 24 June 2010; paper pending published: 14 September 2010; accepted: 27 September 2011; published online: 16 December 2011.

Citation: Vähäkangas K (2011) Chemical exposure as etiology in developmental origin of adult onset human cancer. Front. Pharmacol. 2:62. doi: 10.3389/fphar.2011.00062

This article was submitted to Frontiers in Predictive Toxicology, a specialty of Frontiers in Pharmacology.

Copyright (c) 2011 Vähäkangas. This is an open-access article subject to a nonexclusive license between the authors and Frontiers Media SA, which permits use, distribution and reproduction in other forums, provided the original authors and source are credited and other Frontiers conditions are complied with. 